\title{
H)
}

Volume: 18 Issue: 4 Year: 2021

\section{Leadership capacity and organizational citizenship behavior in educational institutions}

\author{
Mehmet Erdoğan ${ }^{1}$ \\ Gökhan Demirhan ${ }^{2}$
}

\begin{abstract}
In this research, it is aimed to examine the leadership capacity and organizational citizenship levels belong to the teachers working in some schools and the relationship between them. Relational survey design was used in this research. In the 2019-2020 academic year, 4025 teachers working in some primary, secondary and high school levels in the central districts of Uşak province constitute the study group of this research. In this study, the study titled "The adaptation of the leadership capacity scale (Olkö) in schools into Turkish: a validity and reliability study", which was adapted into Turkish, was used to determine the level of organizational citizenship. For analyzing of the data obtained from the participants, arithmetic mean percentage, frequency, standard deviation values were calculated. In the study linear regression analysis and pearson correlation analysis were used. Considering the results of the analysis of this research; the average perception of teachers' leadership capacity behaviors is moderate. Again, according to the results of the research; perception of organizational citizenship behavior on average belonging to teachers is at a "high" level. According to teachers' perceptions, a low, but positive and significant relationship has been found between school leadership capacity and organizational citizenship behavior. Leadership capacity is a significant predictor of organizational citizenship behaviors.
\end{abstract}

Keywords: Leadership capacity; organizational citizenship behavior; education management; school; teacher.

\section{Introduction}

The phenomenon of education plays a vital role for a society in the formation of all its dynamic systems as well as the cultural, social and economic infrastructure in a healthy and efficient manner. In today's world, societies that have made the necessary material and moral investment in education and can ensure its continuation in a systematic order appear as societies that have caught up with the era. Furthermore people are forced to be more competitive, to learn more, and to be more prepared for the equipment their personal lives and jobs can demand from them, with the impact of globalization and individualism. As a result, lifelong learning creates the need to be competitive and is increasingly becoming a necessity in modern society (Maria \& Negrilă, 2018).

\footnotetext{
1 M.A., Uşak University, Department of Educational Sciences, Department of Educational Administration, mehmeterdogan640@,outlook.com (D) Orcid ID: 0000-0001-7731-0718

${ }^{2}$ Lecturer, Ph.D., Uşak University, Department of Educational Sciences, Department of Educational Administration, gokhandemirhan64@gmail.com (D) Orcid ID: 0000-0002-8342-0160
} 
Erdoğan, M., \& Demirhan, G. (2021). Leadership capacity and organizational citizenship behavior in educational institutions. Journal of Human Sciences, 18(4), 514-528. doi:10.14687/jhs.v18i4.6201

It is clear that societies give importance to the education processes of individuals sensitively. In addition, it is important to raise individuals who have been brought up with cultural values, who have the knowledge, skills and equipment required by the age, and who are beneficial for the society. Educational philosophies, thought systems and processes that must be followed in order to achieve the stated goals are important in shaping the educational phenomenon. In parallel with all the scientific and technological innovations, knowledge and skills brought and made necessary by the age we live in, there is a need for a continuous and up-to-date development and updating on behalf of our education system. This need will continue to exist in order to reach the target place among today's world societies and to keep up with the characteristics of the age.

According to Jiao et al. (2013), employee efforts are invaluable for organizational success in a highly dynamic and competitive environment. Organizational managements cannot foresee and plan every situation on their own. Thus, for an effective organizational function in the long run, discretionary performance of employees is needed where they are proactive, adaptable and innovative (Choi, 2007 ; Katz and Kahn, 1978 ; Morrison and Phelps, 1999 ; Moon et al, 2008).In addition, in today's world, leadership and leadership characteristics come to the fore in importance. It is understood that the concept of leadership has an important effect on the education point. In the 21st century, educational leaders will need to be talented, knowledgeable and equipped with diverse and innovative skills (Goldring \& Schuermann, 2009). In parallel with all these developments and reasons, it is necessary to develop leadership capacity and organizational citizenship behavior in educational institutions, which are important in educational processes for the successful, efficient and healthy functioning of education. These phenomena appear as application areas that are increasingly important in the academic field in order to achieve educational goals.

Organizational citizenship behaviors exhibited by all teachers in the educational processes are of vital importance for the implementation of an efficient and effective education and training system. According to Imberman(2009), for organizations to be successful, more than standard role tasks are required due to the ever-increasing competition, complexity and unpredictable change in active business life. The understanding and potential of a positive and strong leadership capacity of an educational institution and teachers is a vital factor beneficial to organizational citizenship behaviors expected to be seen in educational environments (Hoy, Tarter, \& Kottkamp, 1991).DiPaola and Tschannen-Moran (2001)state that the processes created by experts in schools are complex and that organizational citizenship behavior is internally sourced as an aspect of educators' responsibilities and cannot be formally managed through the use of authorities or government influences. In this context, making the necessary arrangements to create a strong understanding of leadership capacity in educational institutions and to develop organizational citizenship behaviors will play a very important role in the realization of education and training processes more efficiently and successfully.

\section{1 Leadership capacity}

The key point in achieving organizational success in an institution is leadership, which has a very important effect on all motivation sources and behaviors of the members of the organization(Bush, 2007; Marion \& Gonzales,2014). According to Brundreet et al.(2003) ,in order to prove their new and unusual educational leadership characteristics outside of official fields, teachers generate new ideas, take part in original studies and demonstrate their professionalism in their fields. Teachers who receive leadership training can acquire leadership behaviors (English, Papa, Mullen, \& Creighton, 2012). Both official and unofficial leadership behaviors and practices together determine a teacher's unique leadership approach and type. Teachers with many years of service at the management and teaching level inspire their colleagues by presenting new ideas and sharing their experiences. These people set general goals. They show professional leadership approaches to their colleagues. Sometimes they supervise them, sometimes they guide them, and they work together to carry out their tasks effectively. They help new start-ups , gather them for 
Erdoğan, M., \& Demirhan, G. (2021). Leadership capacity and organizational citizenship behavior in educational institutions. Journal of Human Sciences, 18(4), 514-528. doi:10.14687/jhs.v18i4.6201

information exchange. As many researchers have found, the teacher leader's job is determined by two kinds of educational leadership factors;"balancing-developing opportunities and improving school". These teachers collect useful data about student work and school-specific environments (Emira, 2010).

With the effect of increasing student output and the restrictions of official authorities, teacher leadership has become an important part of the understanding of innovation in education after 1980(Smylie \& Eckert, 2017). However, more research is needed by advocates of teacher leadership, which allows the teacher to be appointed to positions of leadership involvement, rather than just the role of teaching in the classroom. In order to share leadership and talk about teacher leadership, the school administrator should share his authority with other members and cooperate. It is important to encourage teachers to put forward ideas in new decisions, progress of the school and to give opportunities them for teachers' leadership skills (Smylie \& Eckert, 2017). The subject of teacher leadership, which has not yet emerged, has been researched in different fields and is a subject that should be carefully considered. It should be strengthened and developed to adapt to existing school improvement strategies. By having detailed research and knowledge about teachers, school administrators can gain strength from teachers' leadership contributions and provide a more advanced school management. So, teacher performance also increases and teachers can actively participate in school management processes (York Barr \& Duke, 2004).

According to Hong et al. (2020) leadership capacity consists of both teachers' individual characteristics such as competence, patience and emotions, and social skills such as social accumulation and trust. According to Moran,(2001)and Klassen et al.(2011), leadership capacity is defined as a sense of competence, which is the belief of teachers in their ability to organize and execute the actions necessary to be successful and in a certain context. It is expressed as "fulfilling a specific teaching task" (Moran, Hoy, \& Hoy, 1998). Self-efficacy of teachers' is determined and varied by some different reasons that change from time to time. This shows that it is vital to be professionally taking part in creating environments to promote great teaching for teachers. Besides, current real situation of managerial instability, it is necessary and important for teachers to have both persistence and self-sufficiency to "adapt to changing demands, recover and stay vigorous after changes occur" (Schelvis, Zwetsloot, Bos, \& Wiezer, 2014). According to Day and Gu(2014), resilience shows teachers' motivation and devotion in their daily work multi-dimensionally and socially. Teachers' mental and emotional well-being is also important in their professional lives. In teaching as an emotional profession, emotions determine teachers' success, job satisfaction and well-being. (Schutz \& Zembylas, 2009).

According to Lembeck and Harrison (1996) "A school culture that accepts teacher leadership" is critical to the school climate and culture, and this methodology is an arrangement of "support and prize" that spurs teachers to fill in as pioneers outside the study hall (Little, 1988). At this point, school administrators also play an active and decisive role. So, meeting educators' financial and non-money related requirements "profoundly impacts teachers' shots at having an effect in their readiness to fill in as pioneers"(Katzenmeyer \& Moller, 2001, s. 127). In numerous schools, there is restricted acknowledgment for crafted by teacher pioneers and 'there is no prize for additional work'(Crowther, Ferguson, \& Hann, 2002, s. 34). Albeit "compensating educators who need to go past the homeroom to lead is a mind boggling issue"(Moller \& Katzenmeyer, 1996, s. 34), and a "challenge" (Lembeck\& Harrison, 1996, s. 111 ;Hart, 1990), at last, "educators who lead in defeating errands and critical thinking ought to be empowered and remunerated"(Boles \& Troen, 1996, s. 60). The more the colleague leadership style is adopted by the manager, the more organizational citizenship behavior is evident there(DiPaola \& Tschannen-Moran, 2001, s. 15).School directors ought to characterize significant ways and award teachers as they esteem (Lembeck \& Harrison, 1996, s. 111). 
Erdoğan, M., \& Demirhan, G. (2021). Leadership capacity and organizational citizenship behavior in educational institutions. Journal of Human Sciences, 18(4), 514-528. doi:10.14687/jhs.v18i4.6201

\subsection{Organizational citizenship behavior}

The extra attitudes and behaviors that employees in an organization display voluntarily, apart from the standard behaviors expected from them, are expressed as organizational citizenship behaviors. Although such performances are related to the promotional purpose of the organization, organizational citizenship behavior is observed as pro-social behavior voluntarily displayed by an organization's employees (Organ, 1997). In another definition; organizational citizenship is defined as the series of behaviors that employees exhibit by going beyond the duties assigned to them through their personal commitment to the organization (Bolino, Turnley, \& Bloodgood, 2002). According to Lambert (2006), organizational citizenship behavior (a) goes further than the standard needs about the work, (b) largely discretionary, and (c) beneficial to the organization". According to Puffer (1987)and Karriker and Williams (2009), the work effort that an organization member shows as pro-socially apart from the duties in the job description is defined organizational citizenship behavior.

According to Caldwell et al. (2012), individuals who are thought to show much organizational citizenship behavior typically see it as an internal ethical duty to contribute meaningfully to an organization, and if a person exhibits organizational citizenship behavior, they have an internal code of ethics that motivates them to make a positive contribution to the organization. According to Organ (1997), organizational citizenship behavior is a set of individual actions that increase productivity by creating a positive psychological and social environment in the workplace.

Three important criteria are mentioned in organizational citizenship behavior:

(1) Employees decide to engage in voluntary behavior in the workplace on their own terms.

(2) They can exceed the requirements in their job descriptions.

(3) Their actions bring benefits to organizational effectiveness. These five characteristics can define organizational citizenship behavior : altruism, conscientiousness, sportsmanship, courtesy, and civic virtue (Organ, 1988). According to Organ (1988);

Altruistic employees selflessly help others with work-related problems.

Conscientious employees accept and enforce corporate rules, even if no one follows them

Employees show sportsmanship when they are tolerant without complaints or departures.

Kind employees proactively prevent work-related problems.

Employees demonstrate civic virtue when engaging in society, in terms of the organization's market, industry trends, external threats, competitive advantages and weaknesses. Thesefive characteristics individually contribute to organizational well-being and a positive workplace climate and culture. If the level of organizational citizenship behavior is high in an organization, the organization's competitive advantages increase and its weaknesses decrease.

In this research, it is aimed to examine the leadership capacity and organizational citizenship levels of teachers working in educational institutions and the relationship between them. According to this aim, these research questions were examined;

(1) What is the teachers' level of the perceived leadership capacity in schools and organizational citizenship behavior?

(2) Is there any significant correlation between perceived leadership capacity in schools and organizational citizenship behavior?

(3) Is leadership capacity, a significant predictor of organizational citizenship behavior?

\section{Material and Methods}

In this chapter; the design of the research, the study group, data collection tools and analysis are included.

\subsection{Design}

In this study; relational research design, one of the quantitative survey research types, was used (Fraenkel \& Wallen, 2006). Relational designs provide researchers with the opportunity to 
identify linear relationships between the cases they are studying, as well as give an idea about possible causal relationships between cases (Özmantar, 2019).In this study, the relationship between perceived leadership capacity in educational institutions and teachers' organizational citizenship behavior levels was examined.

\subsection{Population and sample selection}

The sample of the research consists of 295 teachers working in Uşak in the 2019-2020 academic year. While determining the working group, the convenience sampling method was preferred on a voluntary basis, because of the pandemic conditions. Details about the demographic characteristics of the study group are given in the following table 1.

Table 1.Demographic Characteristics of the Sample

\begin{tabular}{|c|c|c|c|}
\hline & & $\mathrm{N}$ & $\%$ \\
\hline \multirow{2}{*}{ Gender } & female & 151 & 51,2 \\
\hline & male & 144 & 48,8 \\
\hline \multirow{7}{*}{ Seniority } & $0-5$ & 29 & 9,8 \\
\hline & $6-10$ & 81 & 27,5 \\
\hline & $11-15$ & 56 & 19,0 \\
\hline & $16-20$ & 48 & 16,3 \\
\hline & $21-25$ & 46 & 15,6 \\
\hline & 26-30 & 19 & 6,4 \\
\hline & 31 and above & 16 & 5,4 \\
\hline \multirow{5}{*}{$\begin{array}{l}\text { Service at } \\
\text { school }\end{array}$} & $0-5$ & 158 & 53,6 \\
\hline & $6-10$ & 88 & 29,8 \\
\hline & $11-15$ & 34 & 11,5 \\
\hline & $16-20$ & 10 & 3,4 \\
\hline & $21-25$ & 5 & 1,7 \\
\hline \multirow{2}{*}{ Marital status } & married & 243 & 82,4 \\
\hline & single & 52 & 17,6 \\
\hline \multirow{3}{*}{$\begin{array}{l}\text { Education } \\
\text { status }\end{array}$} & Associatedegree & 2 &, 7 \\
\hline & bachelor'sdegree & 238 & 80,7 \\
\hline & postgraduate & 55 & 18,6 \\
\hline \multirow{6}{*}{$\begin{array}{l}\text { Managerial } \\
\text { experience }\end{array}$} & no & 197 & 66,8 \\
\hline & $1-3$ & 51 & 17,3 \\
\hline & $4-7$ & 28 & 9,5 \\
\hline & $8-11$ & 8 & 2,7 \\
\hline & $12-15$ & 6 & 2,0 \\
\hline & 16 and above & 5 & 1,7 \\
\hline \multirow{2}{*}{ Age } & $\mathrm{X}$ & \multicolumn{2}{|c|}{ ss } \\
\hline & 39,09 & \multicolumn{2}{|c|}{7,98} \\
\hline
\end{tabular}

According to the table; When the gender variable was examined, the number of female teachers was 151 and the ratio of female teachers was $51.2 \%$, and the number of male teachers was 144 , and the ratio of them was $48.8 \%$. It is understood that the number of female teachers is $2.4 \%$ more than male teachers in the sample. In terms of seniority, the number of teachers with $0-5$ years seniority is 29 , the number of teachers with 6-10 years of seniority is 81 , the number of teachers 
Erdoğan, M., \& Demirhan, G. (2021). Leadership capacity and organizational citizenship behavior in educational institutions. Journal of Human Sciences, 18(4), 514-528. doi:10.14687/jhs.v18i4.6201

with $11-15$ years of seniority is 56 , the number of teachers with $16-20$ years of seniority is 48 , and the number of teachers with 21-25 years of seniority is 46 , the number of teachers with 26-30 years of seniority is 19 , and finally the number of teachers with 31 years and more seniority is 16 .

In the table, according to the data on the length of service at the school, It is understood that the number of teachers with 0-5 years of work is 158 , the number of teachers with a working time of 610 years is 88 , the number of those with a working period of $11-15$ years is 34 , and the number of teachers with a working time of 16-20 years is 10 , and the number of teachers with a working period of $21-25$ years is 5 .

As seen in the table, the educational status of the teachers included in the study, which constitutes the sample, was examined, and it was understood that the number of teachers with an undergraduate faculty graduation was 238 , the number of teachers with a master's degree was 55 , and the number of the teachers with an associate degree was 2.It is understood that most of the teachers in the study are undergraduate graduates. When we look at the table, the average age of the teachers in the study is seen as ss: 7.98 and 39.09.

\subsubsection{School Leadership Capacity Scale}

In the research, the "leadership capacity scale in schools" consisting of 6 dimensions and 30 items, which was developed by Lambert (2003) and adapted into Turkish by Kilınç, Büyüköztürk and Altun(2013)was used.

\subsubsection{The Organizational citizenship behavior scale}

Together with Slcs the "Organizational citizenship behavior scale "developed by Yücel, (2017)consisting of 4 dimensions and 17 items was used after obtaining necessary permissions.

In this study, the structural features of the scales were used as stated by the developers, and the cronbach alpha internal consistency coefficients were calculated to determine the reliability. The results of the reliability analysis of the measurement tools used in our research are given in the table2.

Table 2.Results of reliability analysis of measurement tools

\begin{tabular}{lcc}
\hline Dimension & $\begin{array}{c}\text { Number of } \\
\text { Items }\end{array}$ & $\begin{array}{c}\text { Cronbach } \\
\text { Alpha }\end{array}$ \\
\hline OCB Meticulousness & 5 & 0,803 \\
OCB Virtue & 5 & 0,914 \\
OCB Helpfulness & 4 & 0,864 \\
OCB Sportsmanship & 3 & 0,766 \\
OCB General & 17 & 0,909 \\
SLCS Distributive leadership & 7 & 0,933 \\
SLCS Shared school vision & 9 & 0,960 \\
SLCS Cooperation and shared & 6 & 0,946 \\
responsibility & & \\
SLCS Perceived student & 8 & 0,952 \\
achievement & & \\
SLCS General & 30 & 0,983 \\
\hline
\end{tabular}

*OCB : Organizational citizenship behavior,

*SLCS : School leadership capacity scale

The number of items included in the "meticulousness" sub-dimension of organizational citizenship behavior in the measurement tool was 5 , and the reliability coefficient of 0.803 was reached. The number of items applied in "virtue", one of the sub-dimensions, was 5, and a reliability coefficient of 0.914 was reached. The number of items included in the "helpfulness" subdimension was 4 , and a reliability coefficient of 0.864 was reached. The number of items in the "sportsmanship" sub-dimension was 3, and the reliability coefficient was 0.766.The number of items in the "general" dimension was 17 , and a reliability coefficient of 0.909 was obtained. The 
Erdoğan, M., \& Demirhan, G. (2021). Leadership capacity and organizational citizenship behavior in educational institutions. Journal of Human Sciences, 18(4), 514-528. doi:10.14687/jhs.v18i4.6201

number of items in the "distributive leadership" sub-dimension of the leadership capacity scale was 7 , and a reliability coefficient of 0.933 was reached. The number of items in the "shared school vision" sub-dimension was 9 , and a reliability coefficient of 0.960 was reached. The number of items included in the sub-dimension "cooperation and joint responsibility" was 6 , and the reliability coefficient of 0.946 was reached. The number of items in the "perceived student achievement" subdimension was 8 , and a reliability coefficient of 0.952 was reached. The number of items included in the "general" sub-dimension was 30, and a reliability coefficient of 0.983 was reached.

According to the data obtained in the table in the study, it was seen that the cronbach's alpha coefficients obtained were above the 70 value as accepted in the literature. (Büyüköztürk, Akababa-Altun, \& Kilınç, 2013).In the sub-dimensions and overall of both measurement tools ,according to the calculations regarding the reliability levels, it is possible to state that it has a high level of reliability.

\subsubsection{Data Analysis}

The scales used within the scope of the research were transferred to the online environment due to the pandemic conditions and delivered to the target audience via e-mail and instant messaging applications. The data were collected by examining the answers from the teachers who voluntarily participated in the study. The online data collection process was completed in approximately 2 weeks. The data collected within the scope of the research; in addition to descriptive statistics such as frequency, percentage, arithmetic mean, and standard deviation, pearson product-moment correlation analysis and linear regression analysis were used in accordance with the purpose of the research.

\section{Results}

The sub-dimensions of teachers' leadership capacity and organizational citizenship perception levels, general averages and standard deviations were calculated. Descriptive statistics for teachers' leadership capacity and organizational citizenship perception levels are given in the table 3 .

Table 3.Leadership capacity and organizational citizenship level in schools according to teachers' perceptions (N:295)

\begin{tabular}{lcccc}
\hline & $\mathrm{X}$ & ss & Minimum & Maksimum \\
\cline { 2 - 5 } slcdistributive & 2,7370 &, 77010 & 1,00 & 4,00 \\
slcsharedschoolvision & 2,8008 &, 78349 & 1,00 & 4,00 \\
slccooperationsharedresponsib & 2,8960 &, 78217 & 1,00 & 4,00 \\
ility & & & & \\
slcperceivedstudent & 2,9572 &, 72574 & 1,00 & 4,00 \\
$\begin{array}{l}\text { achievement } \\
\text { slcgeneral }\end{array}$ & 2,8467 &, 72553 & 1,10 & 4,00 \\
$\begin{array}{l}\text { ocbmeticulousness } \\
\text { ocbdvirtueness }\end{array}$ & 4,2583 &, 60417 & 2,00 & 5,00 \\
ocbhelpfulness & 3,9614 &, 83560 & 1,00 & 5,00 \\
ocbsportmanship & 4,1398 &, 70691 & 1,50 & 5,00 \\
ocbgeneral & 3,9345 &, 79554 & 1,33 & 5,00 \\
\hline
\end{tabular}

*slc : School leadership capacity

*ocb :Organizational citizenship behavior

Perception levels of teachers obtained at the point of leadership capacity perceptions; "distributive leadership" ( $\mathrm{X}=2.7370$ ), "shared school vision" ( $\mathrm{X}=2.8008)$, "cooperation and shared responsibility" ( $X=2.8960)$, "perceived student success" ( $X=2.9572)$ and "overall" ( $X=$ 
Erdoğan, M., \& Demirhan, G. (2021). Leadership capacity and organizational citizenship behavior in educational institutions. Journal of Human Sciences, 18(4), 514-528. doi:10.14687/jhs.v18i4.6201

2.8467).Although the values are close to each other; it has been found out that "perceived student achievement" ( $\mathrm{X}=2.9572)$ sub-dimension is higher than "collaboration and joint responsibility", "distributional leadership", "shared school vision" and "general" sub-dimensions. The leadership capacity levels of the teachers were obtained at the "medium" ( $\mathrm{X}=2,8467$ ) level at the "general" sub-dimension point. It was understood that the perceived leadership capacity levels of the teachers were similar in the sub-dimensions. Perceived teacher organizational citizenship behavior levels ( $\mathrm{X}$ $=4.0859)$ were found to be "high". Teacher organizational citizenship perception level subdimensions were found to be close to each other, and it was understood that the value ( $\mathrm{X}=$ 4.2583) in the "meticulousness" sub-dimension was higher than the other sub-dimensions.

At this point, the higher the level of organizational citizenship behavior, the more productive the teachers will be in the educational environments in which they work and positive results will be obtained. Teachers who feel comfortable will devote themselves to their work and put their high motivation, diligence, prudence, helpfulness and sportsmanship attitudes and behaviors into action at a high level, and as a result, the performance of teachers in educational environments will be higher.

The relationship between the perceived school leadership capacity andthe level of organizational citizenship behavior of the teachers participating in the research (Pearson product moments correlation analysis) is given in the table4.

Table 4. The relationship between teachers' perceived school leadership capacity level and organizational citizenship behavior (Pearson product-Moment correlation analysis (N:295)

\begin{tabular}{|c|c|c|c|c|c|}
\hline & 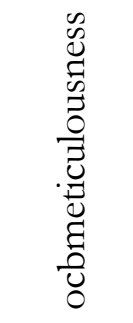 & 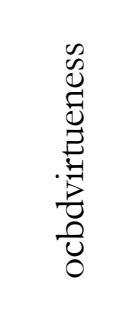 & 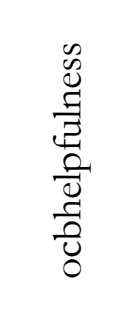 & 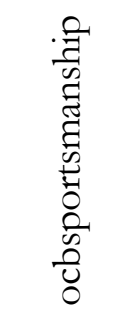 & 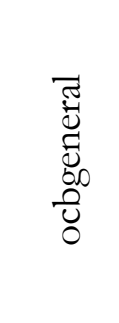 \\
\hline slcdistributive &, $171^{* *}$ &, $252^{* *}$ &, $238^{* *}$ &, $168^{* *}$ &, $273^{* *}$ \\
\hline slcsharedschoolvision &, $122^{*}$ &, $147^{*}$ &, $157^{* *}$ &, $132^{*}$ &, $180^{* *}$ \\
\hline $\begin{array}{l}\text { slccooperationshared } \\
\text { responsibility }\end{array}$ &, $147^{*}$ &, $187^{* *}$ &, $205^{* *}$ &, 075 &, $205^{* *}$ \\
\hline $\begin{array}{l}\text { slcperceivedstudent } \\
\text { achievement }\end{array}$ &, $164^{* *}$ &, $236^{* *}$ &, $244^{* *}$ &, $116^{*}$ &, $253^{* *}$ \\
\hline slcgeneral &, $157^{* *}$ &, $214^{* *}$ &, $219^{* *}$ &, $131^{*}$ &, $238^{* * *}$ \\
\hline $\begin{array}{l}\text { ** Signed correlations } \\
\text { * Signed correlations a } \\
\text { *slc : School leadership } \\
\text { *ocb :Organizational ci }\end{array}$ & $\begin{array}{l}\text { ficant at } \\
\text { icant at } t \\
\text { y } \\
\text { behavic }\end{array}$ & $\begin{array}{l}.001 \text { leve } \\
5 \text { level. }\end{array}$ & & & \\
\hline
\end{tabular}

According to the table, it is seen that there is a positive and low ,statistically significant relationship between the distributive leadership sub-dimension and the sub-dimensions of organizational leadership behavior ; meticulousness $(\mathrm{r}=, 171, \mathrm{p}<0,01)$, virtuousness $(\mathrm{r}=$ ,252,p<0,01), helpfulness $(\mathrm{r}=, 238, \mathrm{p}<0,01)$, sportsmanship $(\mathrm{r}=, 168, \mathrm{p}<0,01)$, general $(\mathrm{r}=$ $, 273, \mathrm{p}<0,01)$.In other words, it can be stated that teachers who have meticulousness, virtuousness, helpfulness, and sportsmanship attitudes are also high in the sub-dimension of "distributive leadership" perceptions. 
Erdoğan, M., \& Demirhan, G. (2021). Leadership capacity and organizational citizenship behavior in educational institutions. Journal of Human Sciences, 18(4), 514-528. doi:10.14687/jhs.v18i4.6201

According to teacher perceptions of leadership capacity levels, it is seen that there is a positive and low ,statistically significant relationship between the "shared school vision" subdimension and the sub-dimensions of organizational leadership behavior ; meticulousness $(\mathrm{r}=, 122)$, virtuousness $(r=147)$, helpfulness $(r=, 157, p<0,01)$, sportsmanship $(r=, 132)$, general $(r=, 180$, $\mathrm{p}<0,01)$.In other words, it can be stated that teachers who have meticulousness, virtuousness, helpfulness, and sportsmanship attitudes are also high in the sub-dimension of "shared school vision" perceptions.

By the teacher perceptions of leadership capacity levels, it is seen that there is a positive and low ,statistically significant relationship between the "cooperation and shared responsibility" subdimension and the sub-dimensions of organizational leadership behavior ; meticulousness $(r=$ ,147), virtuousness $(r=, 187, p<0,01)$, helpfulness $(r=, 205, p<0,01)$, general $(r=, 205$, $\mathrm{p}<0,01)$.Consequently, it can be stated that teachers who have meticulousness, virtuousness, and helpfulness attitudes are also high in the sub-dimension of "cooperation and shared responsibility" perceptions.

According to teacher perceptions of leadership capacity levels, it is seen that there is a positive and low statistically significant relationship between the "perceived student success "subdimension and the sub-dimensions of organizational leadership behavior ; meticulousness $(r=$ ,164,p<0,01), virtuousness $(r=, 236, p<0,01)$, helpfulness $(r=, 244, \mathrm{p}<0,01)$, sportsmanship' $(r=$ ,116 ), general $(\mathrm{r}=, 253, \mathrm{p}<0,01)$.In other words, it can be stated that teachers who have meticulousness, virtuousness, helpfulness, and sportsmanship attitudes are also high in the subdimension of "perceived student success" perceptions.

Within the scope of our research, the effects and statistics of perceived leadership capacity in schools and some demographic variables on the level of organizational citizenship behavior are given in the table5.

Table 5. The effect of perceived leadership capacity in schools and some demographic variables on the level of organizational citizenship behavior

\begin{tabular}{|c|c|c|c|c|c|c|c|c|c|}
\hline \multirow[b]{2}{*}{$\begin{array}{l}\overline{0} \\
\bar{\delta} \\
\dot{\Sigma}\end{array}$} & \multirow[b]{2}{*}{$\simeq$} & \multirow{2}{*}{ 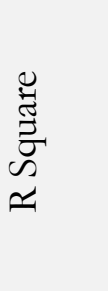 } & \multirow{2}{*}{ 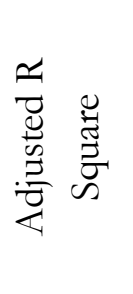 } & \multirow{2}{*}{ 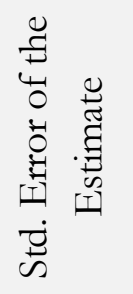 } & \multicolumn{5}{|c|}{ Change Statistics } \\
\hline & & & & & 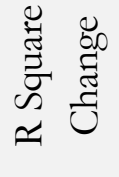 & 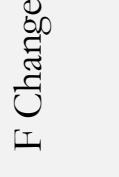 & 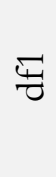 & $\underset{t}{\square}$ & 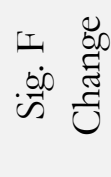 \\
\hline 1 & $238^{a}$ & ,056 & ,053 &, 55447 & ,056 & 17,523 & 1 & 293 &, 000 \\
\hline 2 & $286^{\mathrm{b}}$ & ,082 & ,075 & ,54794 & ,025 & 8,023 & 1 & 292 &, 005 \\
\hline 3 &, $320^{c}$ & ,102 & ,093 & ,54269 & ,021 & 6,670 & 1 & 291 &, 010 \\
\hline
\end{tabular}

a. Predictors: (Constant), Leadership Capacity

b. Predictors: (Constant), Leadership Capacity, Graduation

c. Predictors: (Constant), Leadership Capacity, Graduation, Serving duration at last school

The results of the linear regression analysis conducted to determine the perceived leadership capacity level in schools and the effect of some demographic variables on the level of organizational citizenship behavior are given in table 5.In the regression model created by the Stepwise procedure, independent variables were used in two blocks: the perceived leadership capacity level in schools in the first block, and demographic characteristics consisting of age, length 
Erdoğan, M., \& Demirhan, G. (2021). Leadership capacity and organizational citizenship behavior in educational institutions. Journal of Human Sciences, 18(4), 514-528. doi:10.14687/jhs.v18i4.6201

of service at school, education level and managerial experience in the second block. According to the results of the analysis, the level of leadership capacity variable in the first model explains $5.6 \%$ of the variance in the level of organizational citizenship behavior [F:17,523 $\mathrm{p}<.001]$.

In the second model, the variable of educational status, which is included with the variable of perceived leadership capacity in schools, explains $2.5 \%$ of the variance in the level of organizational citizenship behavior [F:12,983, $\mathrm{p}<.001$ 001].In the third and last model; The variable of length of service at school, which is included with the variables of perceived leadership capacity and educational status in schools, explains $2.1 \%$ of the variance in the level of organizational citizenship behavior [F:11,047, $\mathrm{p}<.001$ 001].

The variables of perceived leadership capacity in schools, educational status and length of service at school explain $10.2 \%$ of the variance in teachers' organizational citizenship behavior levels in total. In other words, the level of perceived leadership capacity in schools ( $\beta: 0.265$, p:.000), educational status ( $\beta: 0.173, \mathrm{p}: .002)$ and length of service at school variables $(\beta: 0.146, \mathrm{p}: .010)$ are the factors that positively and significantly affect the levels of teachers' organizational citizenship behavior. Age and managerial experience variables, on the other hand, were excluded from the model as they did not contribute significantly to the explanation of the variance.

A positive and significant relationship was found between teachers' perceived leadership capacity levels and their sub-dimension levels within their leadership capacity, and their organizational citizenship levels. It can be said that the higher the levels of meticulousness, virtuousness, benevolence, and sportsmanship which are the teachers' leadership capacity subdimensions, the higher the organizational citizenship behavior sub-dimensions such as "distributive leadership", "shared school vision", "collaboration and shared responsibility" and "perceived student success".

As a result, the higher the perceived leadership capacity levels of the teachers, the higher the organizational citizenship levels are expected. At this point, it is expected that supporting and motivating teachers' leadership capacity roles and behaviors by authorities and school administrations will also contribute to organizational citizenship behaviors and this situation will be beneficial in achieving educational goals. On the other hand, the higher the education level of the members working in an educational institution, the more positive the levels of organizational citizenship behavior is affected. In other words, it is possible to state that the level of organizational citizenship increases as the level of education increases. In this respect, teachers' work in the fields of master's and doctorate can be encouraged and supported, and their achievements can be increased by rearranging their career steps.

Finally, as the length of service in a school increases, it is expected that the sense of belonging in that school and the sense of accepting oneself as a part of the organization will increase, and the level of organizational citizenship is expected to increase positively. At this point, social and cultural activities that will make the school and working environment attractive can be increased. The sense of belonging and organizational citizenship behavior levels can be increased by supporting positive posts more, motivation and rewarding attitudes can be given more according to the individual differences and characteristics of the employees, contributing to the desire to stay and work at school for a longer time and to increase the organizational citizenship behavior levels.

\section{Discussion}

The findings obtained in the research conducted to determine the relationship between the leadership capacity and organizational citizenship levels of educational institutions are presented below, firstly about the leadership-leadership capacity, and then about the organizational citizenship part.

In the research we found close values in the distributive leadership, shared school vision, cooperation and joint responsibility and perceived student success sub-dimensions about the leadership capacity perception levels of the teachers participating in our research .In addition a moderate level of leadership capacity was observed at the general level.Kllınç(2013)also has found 
Erdoğan, M., \& Demirhan, G. (2021). Leadership capacity and organizational citizenship behavior in educational institutions. Journal of Human Sciences, 18(4), 514-528. doi:10.14687/jhs.v18i4.6201

close values at the general level and in distributive leadership, shared school vision, cooperation and joint responsibility and perceived student success sub-dimensions in his doctoral thesis titled "Determination of leadership capacity in primary schools". Similar to the data obtained in our study ,he also reached a moderate level of leadership capacity in his research about the leadership capacity perception levels of teachers. According to these results, the leadership capacity levels obtained in these two studies are similar.

On the other hand it was concluded that the perception levels of the participants in the distributive leadership and the shared school vision sub-dimensions were lower, and the perception levels of the sub-dimensions of cooperation and joint responsibility and perceived student success were higher. Regarding this result, it can be said that the administrators and teachers at the school feel common responsibility and consider it necessary to cooperate in exams, meetings and all other processes, which are school studies at the point of cooperation and joint responsibility and perceived student success. Thus, it can be said that student success is internalized as a common responsibility by administrators and teachers. In Gambini's(2011) research, which aims to reveal the ideas of school principals and teachers about the leadership capacity in their schools, he stated that the lowest sub-dimension of leadership capacity was shared school vision. The results are similar to our research in this respect. The fact that the shared school vision sub-dimension in this study is lower than the other dimensions is similar to our study. In addition, the fact that the old management approach is still present in some schools can be shown as a reason for the distributive leadership sub-dimensions not to be at the desired high level. Ogawa and Bossert(2000) stated that the old hierarchical management styles are still maintained in most educational institutions and the old leadership understandings are still dominant in schools and this can be seen as the reason for the relatively low level of perception of the participants towards distributive leadership.

In addition to the data obtained, it is also seen that the general levels of perceived organizational citizenship behavior of the teachers participating in the research are at the "high" level. It was concluded that the sub-dimensions of the perceived organizational citizenship level showed close values, and the "meticulousness" sub-dimension was higher than the other dimensions. Similar to the data obtained from this study, Yllmaz(2017), also evaluated the "total level of organizational citizenship behavior" of the teachers participating in the research as very high in his study investigating the organizational citizenship levels of teachers. Sirrkligil(2015)stated that according to the data he obtained as a result of his research on the perception of organizational citizenship behavior among teachers working in the private and public sectors, the average of organizational citizenship behavior of the teachers participating in the research was slightly below the average. He stated that the teachers participating in the research had the highest average in the "conscientiousness" sub-dimension, while the sub-dimension with the lowest average was in the "sportsmanship" sub-dimension. Although the two studies are not similar in terms of general average organizational citizenship levels, about the data in organizational citizenship behavior subdimensions results are similar.

According to Tezer(2015) and Polat(2007), the existence of teachers with high organizational citizenship behavior levels means; helping their new colleagues in their professional life, participating in activities separate from their routine work willingly and voluntarily, enriching and strengthening the educational environment and conditions. In addition they allocate their time effectively to education and training. In this respect, it is a positive and promising situation that teachers' general organizational citizenship levels are high. As the level of organizational citizenship increases, it will create positive results for teachers and the educational institution they work in.

Based on the results of our research and discussions, the following suggestions can be put forward. It was observed that the average of the leadership capacity levels of the teachers was at the "medium" level in the "general" sub-dimension. In order to maintain and increase this level; an understanding of leadership and school management should be established for an organizational understanding in which all members of the organization will take part, and a leadership culture that learns and develops together in order to reveal the development and positive changes of the school 
Erdoğan, M., \& Demirhan, G. (2021). Leadership capacity and organizational citizenship behavior in educational institutions. Journal of Human Sciences, 18(4), 514-528. doi:10.14687/jhs.v18i4.6201

in every aspect. For this reason, managers should be chosen from people who are visionary, up-todate, prone to change, equipped, active, creative, inspiring and motivating, researching, guiding, sharing and guiding. It may be beneficial for school administrators to have a doctorate or at least a master's degree in education and educational administration.

It is pleasing that the teachers in our study have high levels of organizational citizenship behavior. Because the presence of teachers with a high level of organizational citizenship behavior has very positive reflections on their schools and education. According to Tezer(2015)and Polat(2007)these teachers help their new colleagues in their professional life, they willingly and voluntarily participate in activities apart from their routine work, they enrich the educational environment and conditions, and in addition, they spend their time effectively. Therefore, it is a positive and promising situation that teachers' general organizational citizenship behavior levels are high. As the level of organizational citizenship increases, it will create positive results for the teachers and the educational institution they work in. In order to continue this positive situation;

Parallel to the needs of today's world, it can be ensured that both teachers and administrators are given programs and activities that will provide cooperative learning, healthy, effective and versatile communication and teamwork skills. In order for teachers to understand the importance of leadership and to increase the level of organizational citizenship behavior, a career ladder system that is motivating, increasing school effectiveness and capacity, effective, including material and moral gains and tangible rewards can be rearranged.

Adaptation programs should be offered to newly appointed administrators and teachers simultaneously to gain positive leadership and organizational citizenship behavior and to be encouraged and motivated. It may be beneficial for school administrators to carry out informative and motivating activities by including teachers more in the management processes and by showing approaches to develop and encourage leadership and organizational citizenship behaviors in schools.

Finally, improving the professional rights of teachers and eliminating staff differences can improve their perceptions of organizational citizenship behavior and enable them to be more committed to their profession and to be more productive in the institutions they work.

\section{References}

Ali, U., \& Waqar, S. (2013). Teachers' organizational citizenship behavior working underdifferent leadership styles. Pakistan Journal of Psychological Research, , 28(2), 297-316.

Apaydın, C.., Vilkinas, T., \& Cartan, G. (2011). Predictors of leadership effectiveness for turkish secondary school teachers. Ankara University Journal of Faculty of Educational Sciences, , 44(1), 107-129.

Bass, B. M. (1985). Leadership and performance beyond expectations. Free Press.

Bass, B. M., \& Avolio, B. J. (1995). MLQ multifactor leadership questionnaire. Redwood City, CA: Mind Garden.

Belenkuyu, C., \& Yücel, C. (2017). Organizational citizenship. In S. Özdemir, \& N. Cemaloğlu, Organizational behavior and management (pp. 331-360). Ankara: Pegem Akademi.

Boles, K., \& Troen, V. (1996). Teacher leaders and power : Achieving school reform from the classroom. In G. Moller, \& M. Katzenmeyer, Every teacher as a leader: Realiizng the potential of teacher leadership (pp. 41-62). San Francisco: Jossey-Bass.

Bolino, M., Turnley, W., \& Bloodgood, J. (2002). Citizenship behavior and the creation of social capital in organizations. Academy of Management Review, 27. , https://doi.org/10.5465/amr.2002.7566023.

Brundrett, M., Burton, N., \& Smith, R. (2003). Leadership in education. California: Sage publication.

Bush, T. (2007). Educational leadership and management: Theory, policy, and practice. South African Journal of Education , 27(3), 391-406. . 
Erdoğan, M., \& Demirhan, G. (2021). Leadership capacity and organizational citizenship behavior in educational institutions. Journal of Human Sciences, 18(4), 514-528. doi:10.14687/jhs.v18i4.6201

Büyüköztürk, Ş. (2012). Manual of data analysis for social sciences. (17th ed.). Ankara: Pegem Akademi Yayıncilik.

Büyüköztürk, Ş., Akababa-Altun, S., \& Kıllnç, A. (2013). Adaptation of the Leadership Capacity Scale in Schools to Turkish: Validity and Reliability Study. In Educational Management in Theory and Practice (pp. s.23-46).

Caldwell, C., Floyd, L., Atkins, R., \& Russell, H. (2012). Ethical duties of organizational citizens: Obligations owed by highly committed employees. Journal of Business Ethics , 110, 285-299. http://dx.doi.org/10.1007/s10551-011-1154-9.

Choi, J. (2007). Change-oriented organizational citizenship behavior: Effects of work environment characteristics and intervening psychological processes. Journal of Organizational Behavior, 28(4), 467-484.

Crowther, F., Ferguson, M., \& Hann, L. (2002). Developing teacher leaders. California: Corwin press.

D'Ambrosio, C. L. (2006). Leadership capacity: Principal and teacher perceptions of Lambert's essential elements (Doctoral dissertation). Retrieved from ProQuest Dissertations and Thesis database. (UMI No. 3202729).

Day, C., \& Gu, Q. (2014). Resilient Teachers, Resilient Schools: Building and Sustaining Quality in Testing Times. Abingdon: Routledge.

Deal, T. E., \& Peterson, K. D. (1999). Shaping school culture: The heart of leadership. search.proquest.com .

Doğan, S. (2016). Determination of leadership capacity in primary schools; Bursa province sample master's thesis. Eskişehir.

Ehrhart, M. G. (2004). Leadership and procedural justice climate as antecedents of unitlevelorganizational citizenship behavior. Personnel Psychology, , 57(1), 61-94. .

Emira, M. (2010). Leading to Decide or Deciding to Lead? Understanding the Relationship Between Teacher Leadership and Decision Making. Educational Management Administration \& Leadership, 38(5), 591-612. https://doi.org/10.1177/1741143210373738.

English, F. W., Papa, R., Mullen, C. A., \& Creighton, T. (2012). Educational leadership at 2050: Conjectures, Challenges, and practices. Lanham: Roman \& Littlefield Publishers, INC. .

Ertürk, A. (2020). Liderlik Kapasitesi. Muğla Sitkı Koçman Üniversitesi/ mmw. researchgate.net .

Fraenkel, J., \& Wallen, N. (2006). How to design and evaluate research in education. NY: McGraw-Hill.

Gambini, F. (2011). Leadership capacity for succession and sustainability in a family owned private school (Doctoral dissertation). Retrieved from ProQuest Dissertations and Thesis database. (UMI No. 3465438).

Goldring, E., \& Schuermann, P. (2009). The changing contest of K-12 education administration: Consequences for Ed.D. program design and delivery. Peabody Journal of Education, doi: bttps:/ / doi.org/10.1080/01619560802679583, 84(1), 9-43.

Hart, A. (1990). Impacts of the school social unit on teacher authority during work redesign. American Educational Research Journal , 27(3) 503-532.

Hong, J., Francis, D., Wang, Q., Lewis, L., Parsons, A., Neill, C., et al. (2020). The Role of Trust: Teacher Capacity During School Leadership Transition. Frontiers in Education/Teacher Education https://doi.org/10.3389/feduc.2020.00108.

Hoy, W., Tarter, C., \& Kottkamp, R. (1991). Open schools/Healthy schools Measuring organizational climate. New burry park: CA:Sage.

Humpey, A. (2012). Transformational leadership and organizational citizenship behaviors: The role of organizational identification. The Psychologist-ManagerJournal, , 15, 247-268.

Imberman, M. (2009). Organizational change and organizational justice: Assessing the impact on organizational commitment, change -oriented organizational citizenship behavior, and attitude toward future change. ProQuest Dissertations Publishing, 65-70.

Jiao, C., Richards, D., \& Hackett, R. (2013). Organizational citizenship behaviour and role breadth : A meta-analytic and cross-cultural analysis. Human resource management, 52(5) 697-714 doi : https://doi.org/10.1002/hrm.21555. 
Erdoğan, M., \& Demirhan, G. (2021). Leadership capacity and organizational citizenship behavior in educational institutions. Journal of Human Sciences, 18(4), 514-528. doi:10.14687/jhs.v18i4.6201

Karasar, N. (2005). Scientific Research Method. Ankara: Nobel Publication Distribution.

Karriker, J., \& Williams, M. (2009). Organizational justice and OCB: a mediated multi-foci model. Journal of Management, 35(1), 112-135.

Katz, D., \& Kahn, R. (1978). The social psychology of organizations (2nd ed.). New York: Wiley.

Katzenmeyer, M., \& Moller, G. (2001). Awakening the sleeping giant.Helping teachers develop as leaders (2nd ed.). Thousand oaks california: Corwin.

Kilınç, A. Ç. (2013). Determination of leadership capacity in primary schools, (published doctoral dissertation). Tez.yok.gov.tr. no: 330251.

Kılınç, A., Büyüköztürk, Ş., \& Akbaba-Altun, S. (2013). Adaptation of School Leadership Capacity Scale (OLCS) into Turkish (Olkö); Validity and reliability study. Educational management in theory and practice, 23-46.

Klassen, R., Tze, V., Betts, S., \& Gordon, K. (2011). Teacher efficacy research 1998-2009: signs of progress or unfulfilled promise? Educ. Psychol. Rev. , 21-43. https://link.springer.com/article/10.1007/s10648-010-9141-8.

Korkmaz, E., \& Gündüz, H. B. (2011). Primary school administrators' levels of distributive leadership behaviors. Kalem Journal of Education and Human Sciences , 1(1), 123-153.

Lam, J. (2020). Mediating effects of interpersonal trust, organizational commitment on the relationship between transformational leadership and organizational citizenship behaviour. Los Angeles: ProQuest Dissertations Publishing.

Lam, S., Hui, C., \& Law, K. S. (1999). Organizational citizenship behavior:Comparing perspectives of supervisors and subordinates across four international samples. Journal of Applied Psychology, , 84(A), 594.

Lambert, L. (2003). Leadership capacity for lasting school improvement. Alexandria Virginia: Association for supervision and curriculum development.

Lambert, S. (2006). Both art and science: Employing organizational documentation in workplacebased research. In E. Kossek, \& S. Sweet, The work and family handbook: Multi-disciplinary perspectives, methods, and approaches (pp. (pp. 503-525).). Mahwah: NJ: Lawrence Erlbaum Associates.

Lembeck, E., \& Harrison, J. (1996). Emergent teacher leaders. In G. Moller, \& M. Katzenmeyer, Every teacher as a leader : Realizing the potential of teacher leadership (pp. 101-116). San Francisco: Jossey-Bass.

Little, J. (1988). Assessing the prospects for teacher leadership. In A. Lieberman, Building a professional culture in schools (pp. 78-105(102)). New York: Teacher college press.

Maria, A., \& Negrilă, C. (2018). Lifelong learning in the context of globalization. Economics, Management, and Financial Markets, 403-408.

Marion, R., \& Gonzales, L. D. (2014). Leadership in education: Organizational theory for the practitioner (2nd ed.). Illinois: Waveland press, Inc. .

Martinez, S. D. (2016). Exploring the relationship between school administrators' Leadership Styles and the selfreportof teachers' Organizational Citizenship Behavior, when controlling for follower's age, gender, ethnicity, job tenure, and education.For the degree ofDoctor of P. San Antonio, Texas: Our Lady of the Lake University.

Moller, G., \& Katzenmeyer, M. (1996). The prpmise of teacher leadership .Every teacher as a leader: Realizing the porential of teacher leadership. San francisco: Jossey-Bass.

Moon, H., Kamdar, D., Mayer, D., \& Tekeuchi, R. (2008). Me or we? The role of personality and justice as other-centered antecedents to innovative citizenship behaviors within organizations. Journal of Applied Psychology, , 93(1), 84-94.

Moran, T., \& Hoy, A. (2001). Teacher efficacy: capturing an elusive construct. Teach. Teach. Educ. , 17, 783-805. https://psycnet.apa.org/doi/10.1016/S0742-051X(01)00036-1.

Moran, T., Hoy, A., \& Hoy, W. (1998). Teacher efficacy: its meaning and measure. Rev. Educ. Res. , 68, 202-248. http://dx.doi.org/10.3102/00346543068002202. 
Erdoğan, M., \& Demirhan, G. (2021). Leadership capacity and organizational citizenship behavior in educational institutions. Journal of Human Sciences, 18(4), 514-528. doi:10.14687/jhs.v18i4.6201

Morrison, E., \& Phelps, C. (1999). . Taking charge at work: Extrarole efforts to initiate workplace change. The Academy of Management Journal , 42(4), 403-419.

Ogawa, R. T., \& Bossert, S. T. (2000). Leadership as an organizational quality. In Jossey-Bass reader on educational leadership (pp. (pp. 38-58).). San Francisco:: Jossey-Bass.

Organ, D. (1997). Organizational Citizenship Behavior: It's Construct Clean-Up Time. In https://doi.org/10.1207/s15327043hup1002_2, Human Performance (pp. 10:2, 85-97, ).

Organ, D. (1988). Organizational citizenship behavior: The good soldier syndrome. Lexington Books.

Özmantar, Z. (2019). Types of research commonly used in educational studies. In S. Turan, Research methods in education (pp. s.49-51). Ankara: Nobel.

Özyer, K., Orhan, U., \& Dönmez-Orhan, D. (2012). The Relationship of Demographic Characteristics with the Sub-Dimensions of Organizational Citizenship Behavior: An Application in the Banking Sector. Journal of Dokur. Eylul University Faculty of Economics and Administrative Sciences, , 27(1), 181-204.

Polat, S. (2007). The Relationship Between Secondary School Teachers' Perceptions of Organizational Justice, Organizational Trust Levels and Organizational Citizenship Behaviors. Kocaeli University, Institute of Social Sciences ERIC:ED507710.

Puffer, S. (1987). Prosocial behavior, noncompliant behavior, and work performance among commission salespeople. Journal of Applied Psychology , 72(4), 615-621.

Schelvis, ,. R., Zwetsloot, ,. G., Bos, ,. E., \& Wiezer, N. M. (2014). Exploring teacher and school resilience as a new perspective to solve persistent problems in the educational sector. Teach. Teach. , 20, 622-637. doi: https://doi.org/10.1080/13540602.2014.937962.

Schutz, P. A., \& Zembylas, M. (2009). Advances in Teacher Emotion Research: The Impact on Teachers' Lives. Berlin: Springer Publishing.

Seçer, I. (2013). Practical data analysis with SPSS and LISREL; Analysis and reporting. Ankara: Anı Yayincilik.

Surrkligil, E. (2015). Perception of organizational citizenship behavior in private and public sector teachers / Master Thesis. National Thesis Center.

Sir1kligil, R. (2020). The relationship between leadership capacity and organizational commitment master's thesis. national thesis center.

Smylie, M. A., \& Eckert, J. (2017). Beyond superheroes and advocacy: The pathway of teacher leadership. Educational Management Administration \& Leadership, , 46(4), 556-577. https://doi.org/10.1177\%2F1741143217694893.

Tabachnick, B., \& Fidell, L. (2013). Using multivariate statistics. Boston: Pearson.

Tezer, A. (2015). The Relationship Between Organizational Citizenship Behaviors and Motivation of Primary School Teachers (Master's Thesis). National Thesis Center.

Yilmaz, H. (2017). The effect of authentic leadership, Machiavellianism and Johari window on organizational citizenship behavior in educational institutions. National Thesis Center no : 475484.

York Barr, J., \& Duke, K. (2004). What Do We Know About Teacher Leadership? Findings From Two Decades of Scholarship. Review of Educational Research , 74(3):255-316 https://doi.org/10.3102\%2F00346543074003255. 